\title{
Observing Solidification Patterns in Rapidly Solidified Alloys and Powders
}

\section{James H. Steele Jr. Ph.D, Consultant, 7412 Singing Hills Court, Boulder, CO 80301}

The preparation of rapidly solidified alloy samples for backscatter electron imaging in the SEM can be accomplished using the Bi-Sn pressure impregnation technique described by Steele [1]. In this case an Al foil bag is used to hold samples of rapidly solidified powders, which keeps them from spreading and allows cross sections of the powder aggregate to be obtained by standard metallographic polishing techniques followed by Argon ion etching. The pressure mounting and expansion of the Bi-Sn alloy upon solidification yields excellent retention of the powder particles during mechanical polishing. The metallic matrix also provides the necessary conductivity for argon-ion etching to be used to expose the solidification patterns within the microstructure of the rapidly solidified particles.

Figure 1 shows a classic dendritic solidification pattern within a Ni-based superalloy rapidly solidified powder particle. The contrast is a result of a combination of the topography created by differential etching rates and atomic number contrast from alloy segregation in the interdendritic regions.

Figure 2 shows the solidification pattern within a $\boldsymbol{\gamma}$-TiAl rapidly solidified alloy powder particle (Composition: $\mathrm{Ti} / 32 \boldsymbol{w} / \% \mathrm{Al} / 5 \boldsymbol{w} / \% \mathrm{Nb} / 1 \boldsymbol{w} / \% \mathrm{Ta} / 0.15 w / \% \mathrm{C} / 0.20 w / \% \mathrm{O}$ ) produced by a rotating disk method. The grey contrast representss lower atomic number contrast showing higher Al content in the cell boundary regions. Very fine internal microporosity can also be observed as black contrast.

Figure 3 shows the cellular solidification pattern within an E-beam weld of Fansteel 85. The grey contrast represents lower atomic number contrast for the higher $\mathrm{Nb}$ content in the cell boundary regions. The grain boundaries in the weld are observed because of the different argon ion etching rates for different crystal orientations. Some of the cells can be observed to cross the grain boundaries indicating that the cellular segregation pattern was in place when the grain boundaries moved to their final positions.

References

[1] Steele J.H. Jr. , Microsc. Microanal. Vol 8 (Suppl. 2), 2002, 1260CD. 
Figure 1 Inverted backscatter image of a dendritic solidification pattern in an experimental Ni-based rapidly solidified superalloy powder particle. The pattern suggests that nucleation was from a single source within the original liquid droplet. The alloy composition:

$$
\begin{aligned}
& \mathbf{N i}=70 w t \% / \quad \mathbf{A l}=9 w \mathrm{wt} \% \\
& \mathbf{C r}=3 w \mathrm{t} \% \quad / \quad \mathbf{M o}=9 w \mathrm{t} \% / \\
& \mathbf{W}=9 w \mathrm{w} \% .
\end{aligned}
$$

Figure 2 Backscatter image of a solidification pattern in a $\gamma$-TiAl solidified superalloy powder particle.

The alloy composition:

$$
\begin{aligned}
& \mathbf{T i}=61 w \boldsymbol{t} / \% / \mathbf{A l}=32 \boldsymbol{w t} / \% \\
& \mathbf{N b}=5 \boldsymbol{w} / \% \quad / \mathbf{T a}=1 \boldsymbol{w t} / \% \\
& \mathbf{C}=0.15 \boldsymbol{w t} / \% / \mathbf{O}=0.20 w \boldsymbol{t} / \%
\end{aligned}
$$
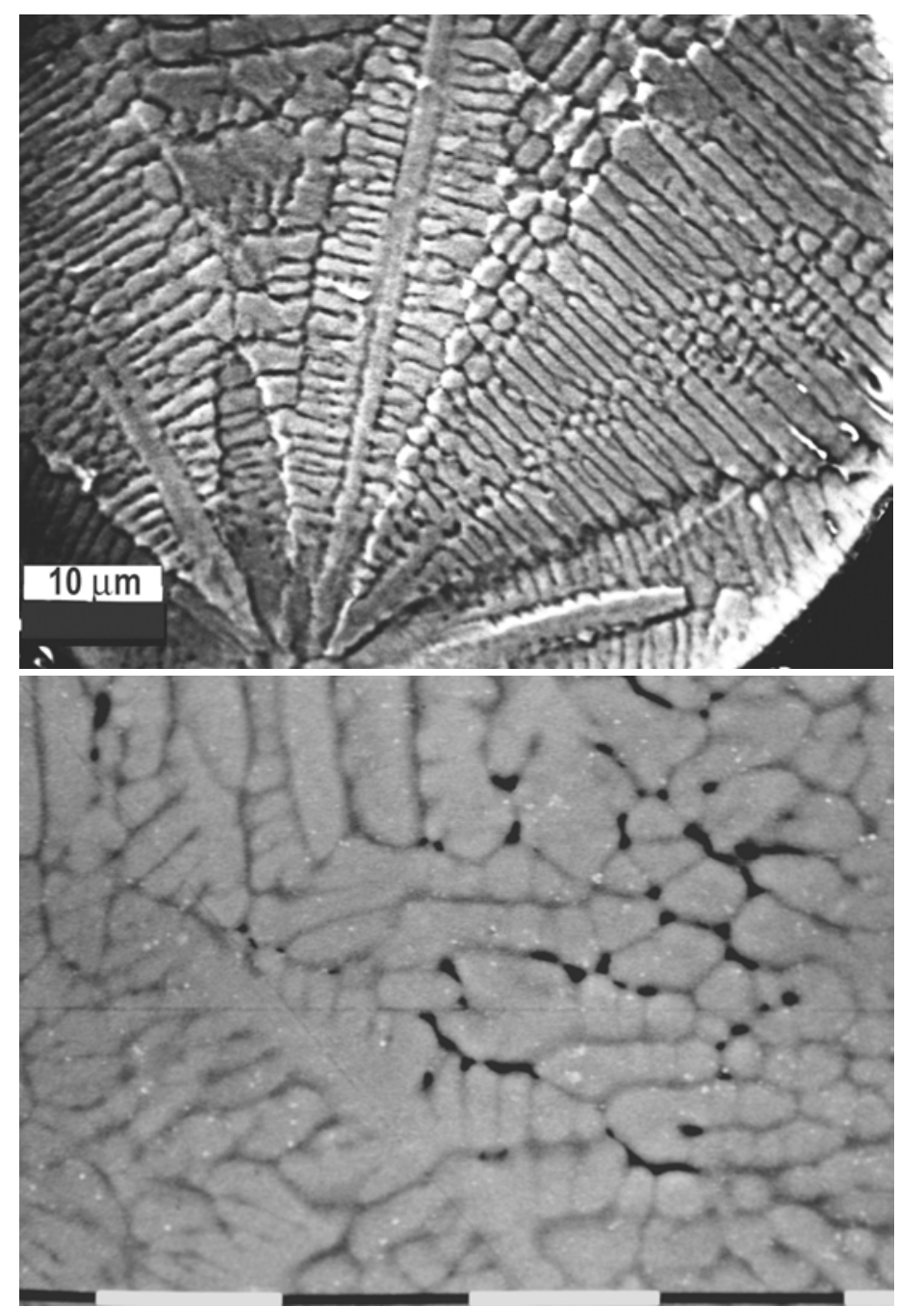

Figure 3 Backscatter image of the cellular solidification pattern in an E-beam weld of Fansteel 85. The EDS spectra from the light gray $\mathrm{Nb}$ rich regions show the alloy segregation of $\mathrm{Nb}$ in the cell boundaries.

The alloy composition:

$\mathbf{T a}=45 w t / \% \quad / \mathbf{N b}=55 w / \%$
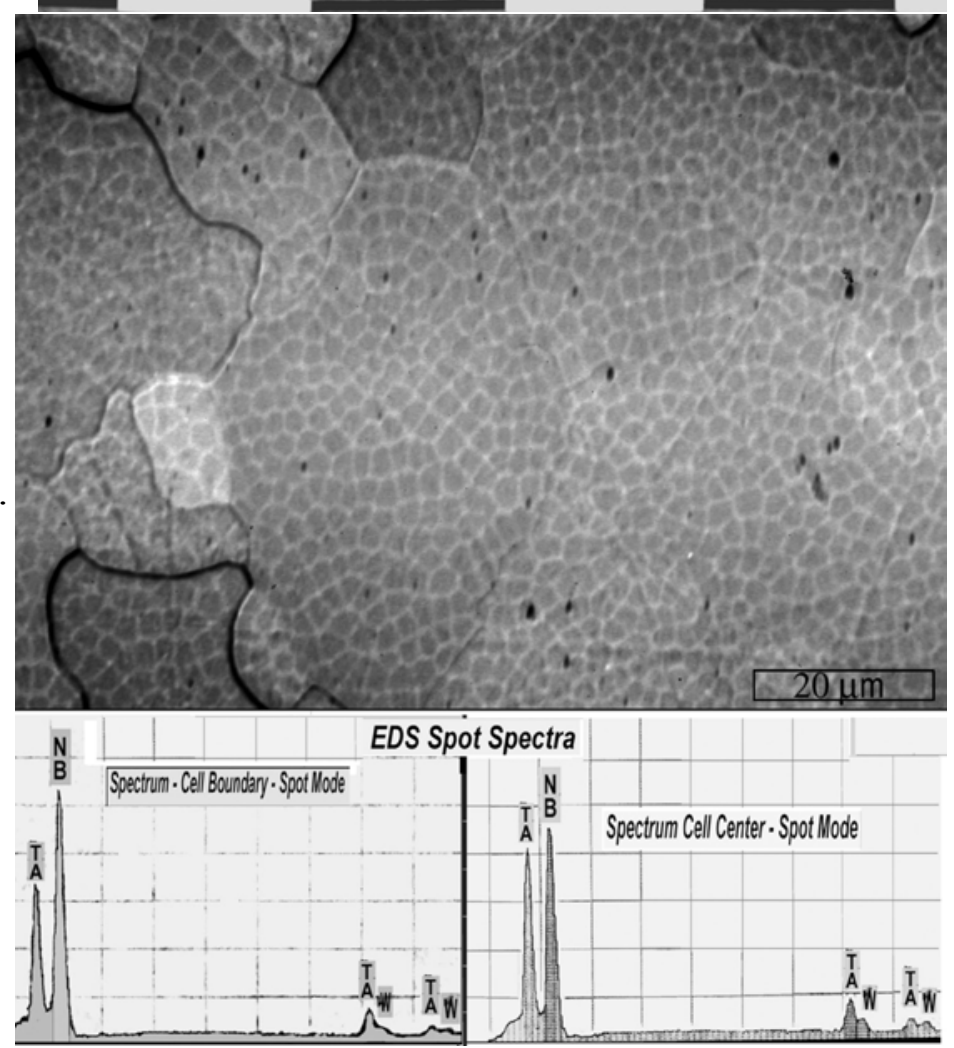